\section{Stopping antiepileptic drugs - other factors to consider}

Aust Prescr 2021:44:78

https://doi.org/10.18773/austprescr.2021.024

I read the informative article 'Discontinuation of antiepileptic drugs in adults with epilepsy' by Hanka Laue-Gizzi' and would like to highlight a few points regarding the factors which can affect the outcomes for patients.

The author described factors associated with seizure recurrence. A few more factors worth mentioning include the type of seizure, neurological examination, and any family history of epilepsy. Patients who had a single seizure type have more chance of remaining seizure-free after drug withdrawal. Generalised seizures have a better prognosis compared to focal seizures. Patients with a normal neurological examination have more chances of remaining seizure-free after drug withdrawal as do patients with no family history of epilepsy. ${ }^{2}$

The article also described important considerations for counselling. Apart from driving, patients should refrain from potentially dangerous activities such as swimming during the first three months after discontinuing therapy. ${ }^{2}$

Ajay Kumar Shukla

Assistant professor, Department of Pharmacology, All India Institute of Medical Sciences, Saket Nagar, Bhopal, Madhya Pradesh, India

\section{REFERENCES}

1. Laue-Gizzi H. Discontinuation of antiepileptic drugs in adults with epilepsy. Aust Prescr 2021:44:53-6. https://doi.org/10.18773/austprescr.2021.005

2. Lowenstein DH. Seizures and epilepsy. In: Jameson JL, Fauci AS, Kasper DL, Hauser SL, Longo DL, Loscalzo J, editors. Harrison's principles of internal medicine. 20th ed. New York: McGraw-Hill; 2018. p. 3050-68. 